\title{
SOCIO-ECONOMIC AND ENVIRONMENTAL IMPACTS OF COTTON CULTIVATION (Gossypium) IN THE ARRONDISSEMENT OF AKLAMKPA (MUNICIPALITY OF GLAZOUE)
}

\author{
TCHAOU A. Gabin and HOUNZINME S. Sylvie \\ Laboratoire d'Etudes des Dynamiques Urbaines et Régionales (LEDUR)/FASHS/UAC
}

https://doi.org/10.35410/IJAEB.2021.5675

\begin{abstract}
Cotton is the main cash crop in Benin. Cotton cultivation is an important source of income for the Aklamkpa District. The income from this sector contributes to the improvement of the living conditions of the populations. The main objective of this study is to contribute to a better understanding of the socio-economic impacts of cotton cultivation in the Aklamkpa District.

The methodological approach adopted includes documentary research, field work, demographic data from 1979-2013, cotton production statistics, data processing with Word and Excel software.

The analysis of the results has been done. The results obtained show that income from the marketing of cotton production has contributed $85 \%$ to the improvement of people's living conditions. Cultivation techniques suggest a degradation of the vegetation cover and the acceleration of the depletion of the soil of the study area. Faced with such a situation, more than $90 \%$ of producers adopt endogenous strategies to adapt to cotton production. In doing so, it is important to develop new methods of cotton production, diversify agriculture, adopt organic cotton cultivation and propose measures for the rational management of the environment.
\end{abstract}

Keywords: Aklamkpa, cotton, impacts, socio-economic, environment.

\section{INTRODUCTION}

Called Gossypium in Latin and Hasy in Malagasy, cotton is a perennial plant with a taproot and can grow over a meter in the ground. There are short, medium and long silk cotton. It is of quality when its fiber has a commercial reach. The general appearance and size of the cotton plants are variable. Cotton trees are perennials and shrubs. Some wild cotton plants can reach the size of a small tree, but most species do not exceed the size of 1 to $1.50 \mathrm{~m}$ (F. Afouda et al, 2014, p. 215). In fact, cotton is the main fiber crop in the world. In most African countries including Benin, cotton is the basis of development and contributes considerably to the employment and income of rural populations (J.U.Dossa, 2007; p.43).

In Benin, after the decline in oil palm production due mainly to an unfavorable climatic context, cotton has become the main export crop organized in the sector. Cotton has so far been a vital resource for several West African countries (I. Yabi, 2007, p. 44). This speculation remains the driving force behind the entire national agricultural production system (I. Yabi, 2007, p.45). To this end, about $95 \%$ of cotton lint production is exported, representing $80 \%$ of export earnings and contributing significantly to the improvement of the national trade balance (ONS, 2013). 
Vol. 06, No. 05; 2021

ISSN: $2456-8643$

This sector remains by far the best organized in the country $(\mathrm{H}$. M. Batamoussi, I. Moumouni, and S. B. J. Orou Tokore Mere, 2015, p.123). However, in recent years Benin's "white gold" has been accused of contributing to the degradation of natural resources. Indeed, the production of conventional cotton is the largest consumer of pesticides and chemical fertilizers (V. A. Houndekon, 2010, p.65). It has led to an intensification of agriculture with the consequent excessive use of chemicals.

But this boom in the use of this type of input is considered the only alternative to increase yields and production in order to respond effectively to the ever-growing demand from the textile industries (A. Hougni, PC Kpadé, et al. AC Djihinto, 2012, 79).

However, the use of chemicals is harmful to the environment and also has an impact on the health of agricultural workers who handle them and spray them. For the past ten years or so, notable efforts have been made to develop environmental sustainability by significantly reducing inputs. The price of transfer of inputs becomes more and more expensive. At the same time, insect resistance and the proliferation of certain pests lead to lower yields. Thus the excessive use of fertilizers and pesticides results in human intoxication and contributes to environmental degradation and with the low production recorded; which leads to the abandonment of cotton production by some farmers (I. Dossounon, 2003, p.56).

According to recent statistics from the Directorate General of Economic Affairs (DGAE, 2020, p.1), the growth rate of the Benin economy has accelerated over the last four (04) years 20162019. From 3.3\% in 2016, the growth rate of the economy stood at $6.7 \%$ in 2019 and this increase in the growth rate is partly attributable to the good performance of cotton production which did not has stopped reaching record levels since 2016. The same source specifies that cotton production rose from 450,000 tonnes in 2016 to 678,000 tonnes in 2018. For 2019, it was 732,372 tonnes. Production therefore recorded a considerable increase between 2016 and 2019, an increase of $8 \%$ between 2018-2019. This performance placed Benin at the forefront of cotton producers in West Africa from 2018 to 2019 (DGAE, 2020, p.2).

Considering all these records broken by Benin in recent years (2016-2019), and the place given to cotton cultivation as a speculation having an economic, political and also social impact on the fight against poverty, the one could a priori accept a hypothesis according to which the wellbeing of cotton producers should improve.

Despite its performance in recent years, the cotton sector is experiencing difficulties linked to its mismanagement by the various actors, to the fluctuation of costs on the international market and causes a deterioration of the living environment of the first actors (cotton growers). that the industry is going through require in-depth thinking. It is to better understand the different facets of this situation that this article is entitled "Socio-economic impact of cotton cultivation in the Aklamkpa district (Municipality of Glazoué)".

\section{MATERIALS AND METHODS}

\subsubsection{Sampling and database}

The research units concerned by this study are, on the one hand, the institutions or structures that play a determining role in the cotton sector and, on the other hand, producers and village cooperatives in the study sector. For the choice of sampling, three criteria were taken into account: the size of the agricultural population, the level of production at least $1000 \mathrm{~kg} / \mathrm{ha}$ at yield and the presence of a cooperative per village (at least two cooperatives). 
Following the exploratory survey, a few villages in the Arrondissement were identified. At the level of each cooperative present in these villages, producers are taken on the basis of the average level of sown cotton areas. This average level in the Arrondissement is 1 ha as the limit for distinguishing producers. At the level of structures, the survey took into account those responsible, including 18 for village cotton production cooperatives (CVPC) due to 01 per CVPC from the 18 investigative villages, ie eighty-nine (89) producers; 04 supervisory staff; 01 input distribution manager and 02 health workers.

The size of the sample that served as the basis for the individual surveys of producers and managers of structures was made by reasoned choice and is therefore composed of eighty-nine (89) people (Table I) and seven ( 07) responsible.

Table I: Distribution of respondents by cooperative by village in the Arrondissement.

\begin{tabular}{|l|l|l|l|l|}
\hline Arrondissement & Villages/ & $\begin{array}{l}\text { Name } \\
\text { CVPC }\end{array}$ & $\begin{array}{l}\text { Workforce per } \\
\text { cooperative }\end{array}$ & $\begin{array}{l}\text { Staff } \\
\text { surveyed }\end{array}$ \\
\hline \multirow{5}{*}{ Aklamkpa } & Mindedjro & 05 & 44 & 05 \\
\cline { 2 - 5 } & Longbondjindji & 02 & 29 & 02 \\
\cline { 2 - 5 } & Soutedji & 10 & 126 & 10 \\
\cline { 2 - 5 } & Affignidedji & 02 & 21 & 02 \\
\cline { 2 - 5 } & Agbagbadji Sowiandji & 05 & 60 & 05 \\
\cline { 2 - 5 } & Akpladogbandji & 10 & 120 & 10 \\
\cline { 2 - 5 } & Danzogodji & 10 & 103 & 10 \\
\cline { 2 - 5 } & Agbagbadji 1 & 02 & 31 & 02 \\
\cline { 2 - 5 } & Lewodjo & 02 & 38 & 02 \\
\cline { 2 - 5 } & Sewedji & 05 & 38 & 05 \\
\cline { 2 - 5 } & Amangavissa & 05 & 33 & 05 \\
\cline { 2 - 5 } & Antadji & 05 & 50 & 05 \\
\cline { 2 - 5 } & Lagbo & 10 & 116 & 02 \\
\cline { 2 - 5 } & Dandji Doho & 05 & 63 & 02 \\
\cline { 2 - 5 } & Severin Djamandji & 05 & 77 & 02 \\
\cline { 2 - 5 } & Sowiandji & 02 & 68 & 02 \\
\cline { 2 - 5 } & Tognon Djamandji & 02 & 96 & 02 \\
\cline { 2 - 5 } & Yombo Doho & 02 & 78 & 02 \\
\cline { 2 - 5 } & Total & 89 & & 0 \\
\hline
\end{tabular}

Source: Field survey, July 2020.

According to the analysis of Table I, 89 producers were interviewed in 18 villages of the Arrondissement and to these, are added 7 different agents involved in the field of cotton production in the said arrondissement. A total of 96 people were interviewed on cotton production in Aklamkpa.

Several methods are used in the processing of the information collected. 


\subsection{Data collection and processing method}

The techniques used made it possible to collect data related to the socio-demographic and economic characteristics of producers and to the quantities, prices of inputs and outputs engaged in cotton production using an individual questionnaire and semi-structured interviews.

Several statistical and cartographic methods were used in this study to process the information collected. With regard to the processing of the data, we proceeded to an examination of the questionnaires in a manual way. A check was made in order to eliminate over time the elements that could distort or influence the meaning of the data. Finally, the summary tables were drawn up using the appropriate software (Word, Excel and Map Infos). Word is a software intended for entering text, Excel was used for making graphics and tables and Map Infos for making maps.

\section{RESULTS}

\subsection{Physical and human conditions favorable to cotton production}

Aklamkpa District is a district of the Municipality of Glazoué. It is made up of six (06) villages or city districts. Between $8^{\circ} 0^{\prime} 0$ "and $8^{\circ} 30^{\prime} 0^{\prime \prime}$ North latitude and $2^{\circ} 0^{\prime} 0$ "and $2^{\circ} 20^{\prime} 0$ " East longitude, the Borough of Aklamkpa is limited:

- To the north by the municipalities of Bassilla and Ouèssè;

- To the south by the districts of Thio and Ouèdemè;

- To the east by the Communes of Ouèssè and Savè and

- To the west by the Communes of Savalou and Bantè (figure 2).

On the demographic level, the Aklamkpa District had a population of 6,514 inhabitants according to the 1979 census. This population increased from 9,187 inhabitants in 1992 and 16,895 inhabitants in 2002. This District has a population of 25,756 inhabitants in 2013 including 12,845 men, or $49.87 \%$ and 12,911 women, or $50.12 \%$ of the total population; an increase of 8861 in 11 years; which corresponds to a growth rate of $6.2 \%$.

The population of Aklamkpa Ward grew steadily from 1979 to 2013.

This increase is strongest in 2002 and 2013. From 1979 to 2013, the population of Aklamkpa District increased significantly. As a result, agricultural assets change as the demographic rate changes.

Compared to the demographic growth of Aklamkpa District, field surveys and analysis of INSAE data show that the number of agricultural workers increased considerably from 2002 to 2013. 
Vol. 06, No. 05; 2021

ISSN: 2456-8643

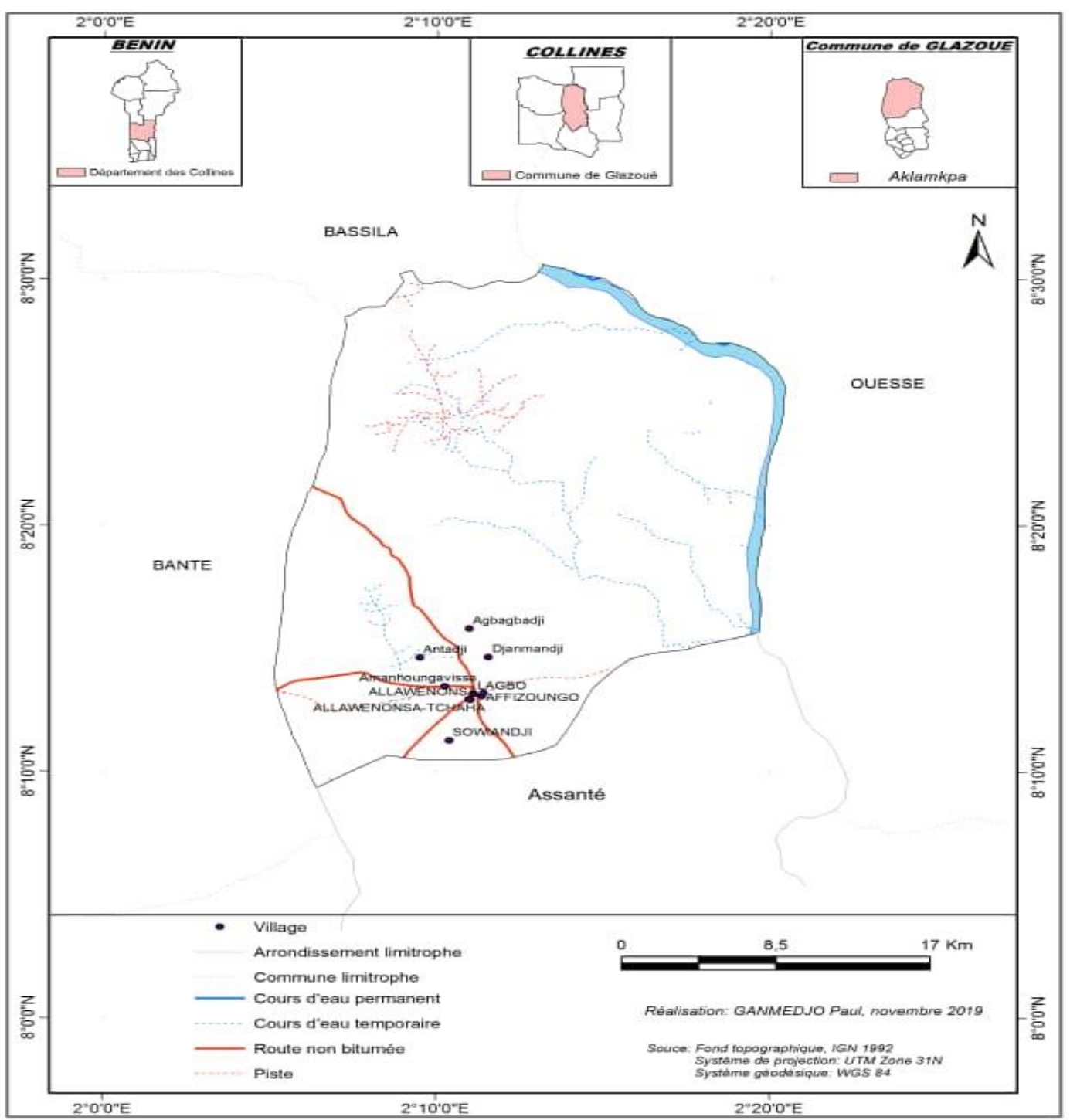

Figure $\mathbf{n}^{\circ}$ 1: Geographical location of the study area

Source: Topographic base map at 1/200000, IGN

From a geomorphological point of view, the study region is based on an old crystalline basement dating from the Precambrian (E. Ogouwalé, 2006, p.76). The geological formations made up of granite-gneissic elements have been eroded to generate a peneplain which is generally inclined from north to south with an average altitude culminating between 200 and $300 \mathrm{~m}$ (I. Yabi et al, 2008; p.319).

As for the pedological components, the most important soils in this sector are tropical ferruginous soils, hydromorphic soils and ferralitic soils. According to I. Yabi et al, (2008; 
Vol. 06, No. 05; 2021

ISSN: $2456-8643$

p.316), tropical ferruginous soils on granite-gneissic basement are more or less concreted and leached with low-slope shells. All of these soils, in relation to the geological and morphological units, constitute an important potential for agricultural activities in the study area. These soils have very favorable cultural aptitudes for the cultivation of tubers, cereals, peanuts, cotton and others (F. Afouda et al, 2014, p. 33).

From a climatic point of view, the Aklamkpa district belongs entirely to the Sudano-Guinean climate zone with two rainy seasons and two dry seasons with hazards. Annual precipitation varies between 1000 and $1200 \mathrm{~mm}$ per year. Thus, during a normal year (when the distribution of rainfall is normal), the cotton plant would be in good conditions to meet its water needs and therefore give a good yield. In fact, the cotton plant needs more than $700 \mathrm{~mm}$ of water evenly distributed during its vegetative cycle. In this study area, the average temperature varies between 27 and $31^{\circ} \mathrm{C}$. The daily thermal amplitude is overall $8.5^{\circ} \mathrm{C}$ but at times it reaches $10^{\circ} \mathrm{C}$ north of the study area (F. Afouda, 2010, p.140). It corresponds to the thermal requirements of the cotton plant which develops better when the average temperature varies between $26^{\circ} \mathrm{C}$ and $28^{\circ}$ C (E. Ogouwalé, 2006, p.188). The period of sunshine is around $7 \mathrm{~h} /$ day, which is more than enough to cover the needs of the plant. Relative humidity is around $80 \%$ with a lot of variation especially in the August period.

Ultimately, the average climatic conditions of the area are favorable to rain-fed cotton production. The physical environment of the studied sector constitutes a potential for cotton cultivation. This natural potential is valued by the population whose primary occupation is agriculture. In fact, agricultural workers in the study sector make up about $71 \%$ of the total population (INSAE, RGPH4-2013). It should be noted that the peasants organize themselves to produce cotton on varying areas.

\subsection{Some determinants of cotton production in Aklamkpa district}

One of the determinants of cotton production analyzed in the sector are the different modes of access to land.

Land plays an essential role in the social and economic life of the populations in the study area and therefore constitutes the primary essential support for cotton fields. Its access, acquisition and use follow rules and vary according to socio-cultural groups in the study region.

In addition, socio-anthropological investigations have shown that in the study area, land inheritance follows a patrilineal regime, that is to say transmitted from father to son in most cases. The division takes place during the lifetime or often after the death of the father. The land of the deceased is shared between these sons who are the beneficiaries and the privileged.

As for the loan of land, it is a free loan to anyone who requests it from their owner. This mode of access to land is often practiced among family members and sometimes extends to friends. However, this mode of access to land does not guarantee security for the borrower because at any time the owner of the land can claim his space even without notice. There is also the purchase of agricultural land which is gaining momentum in the community. 
Cotton production influences the socio-economic life of producers. It is therefore necessary to develop endogenous strategies for good cotton production. This research is devoted to the study of socio-economic indices of culture.

\subsection{Socio-economic impacts of cotton production}

They are all the costs of agricultural inputs and cultivation operations, the average yield per hectare of cotton, the primary marketing of seed cotton, the average income per hectare and the destination of the income from cotton production.

\subsubsection{Agricultural input costs}

The chemical inputs used in the cultivation of cotton per hectare and their costs are listed in Table II.

Table II: Costs of agricultural inputs per hectare of cotton

\begin{tabular}{|l|l|l|}
\hline \multicolumn{1}{|c|}{ Inputs } & \multicolumn{1}{c|}{ Quantity / ha } & \multicolumn{1}{c|}{ Costs in (FCFA) } \\
\hline NPK SB & $200 \mathrm{~kg}$ & 48.000 \\
\hline Urea & $50 \mathrm{~kg}$ & 12.000 \\
\hline Insecticides & $05 \mathrm{~L}$ & 17.500 \\
\hline Herbicides & $04 \mathrm{~L}$ & 14.000 \\
\hline Spray devices & 01 & 34.900 \\
\hline Piles & 15 paires & 3.000 \\
\hline Total & & $\mathbf{1 2 9 . 4 0 0}$ \\
\hline
\end{tabular}

Source: Field survey, July 2020

Estimates of the costs of agricultural inputs are made on the basis of standards adopted by supervisory services and the cost of the products offered on the market. In reality, the use of inputs depends on the soil from one village to another. Under normal production conditions, 129,400 FCFA are required for one hectare of cotton. This amount represents approximately $36 \%$ of the gross revenue from a production of $1400 \mathrm{~kg} / \mathrm{ha}$ of premium seed cotton. This percentage would apply to $85 \%$ of the farmers in the sample with a yield greater than or equal to $1400 \mathrm{~kg} / \mathrm{ha}$. However, cotton cultivation requires operations before obtaining a good yield.

\subsubsection{Costs of cultivation operations}

Cotton cultivation requires about ten cropping operations. The activities are carried out at the same time by the agricultural assets of the household and the agricultural workers. The cost of operations is estimated on the basis of the cultivation practices induced by the technical support services in force in the Arrondissement. The results of the surveys show that we can distinguish five (05) types of dominant cropping operations. These results are shown in Table III. 
Table III: Estimation of the costs of cropping operations per hectare of cotton

\begin{tabular}{|l|l|}
\hline Types of operations & Operation costs (FCFA) \\
\hline Clearing & 5.000 \\
\hline Labour & 30.000 \\
\hline Semis & 2.000 \\
\hline Sarclage & 12.000 \\
\hline Harvest & 60.000 \\
\hline Fertilizer input & 12.000 \\
\hline Insecticide treatment & 1.500 \\
\hline Total & $\mathbf{1 2 2 . 5 0 0}$ \\
\hline
\end{tabular}

Source: Field survey, July 2020

Table III shows that cotton cultivation undergoes seven benefits. The harvest comes first with the cost significantly higher than those of the others which amount to 60,000 FCFA, plowing costs 30,000 FCFA, weeding 12,000 FCFA, fertilizer input at 12,000 FCFA, sowing at 2,000 FCFA and finally the least expensive service is the insecticide treatment which consumes 1,500 FCFA. After these expenses, we end up with a yield of seed cotton.

\subsubsection{Average yield per hectare of cotton.}

The yield takes into account the villages in the study frame over the period of 2019.

Table IV shows the average yield per hectare in the villages in 2019.

Table IV: Average yield per hectare of cotton production in Aklamkpa.

\begin{tabular}{|l|l|l|}
\hline Villages & Yield in Tons / ha & Yield in kg / ha \\
\hline Affizoungo I & 1,100 & 1100 \\
\hline Affizoungo II & 1,200 & 1200 \\
\hline Allawenoussa I & 1,300 & 1300 \\
\hline Allawenoussa II & 1,200 & 1200 \\
\hline Lagbo & 1,200 & 1200 \\
\hline Sowignandji & 1,0 & 1000 \\
\hline
\end{tabular}

Source: CVPC and Field survey, July 2020

Analysis of this table reveals that the average yield per hectare varies from village to village. Of the six (06) villages of the Arrondissement, it is in the village of Allawenoussa I which harvests $1300 \mathrm{~kg} /$ ha and the village of Sowignandji which arrives last with 1000kg as harvest / ha. These returns are a factor in the quality of the land and the wise use of inputs. These harvests are thus intended for marketing.

\subsubsection{Primary marketing of seed cotton}

The primary marketing of seed cotton is organized in local markets between producers and the heads of village cotton producers' cooperatives in Aklamkpa District, under the supervision of 
Vol. 06, No. 05; 2021

ISSN: $2456-8643$

supervisory staff. It marks the end of the agricultural campaign and allows producers to see the fruits of their labor. The price of seed cotton is set at the start of the marketing season by the government and producer representatives. According to field surveys, cotton prices vary depending on the choice (harvest). Thus, the choice price is sold at $265 \mathrm{f} / \mathrm{kg}$ and the second choice at $215 \mathrm{f} / \mathrm{kg}$, i.e. a difference of $50 \mathrm{f}$. At this level, it must be said that the quantity of cotton sold at the first choice is greater than that sold at the second choice since most of the second choice cotton contains waste which justifies the reduction in price.

For sale, the cotton growers transport the seed cottons to a place "called the market for the occasion" by lot or heap by producer and, with the scales, they weigh each other to fill trucks which are responsible for conveying them to the factories. A few large producers transport for them directly for weighing at the plant level.

\subsubsection{Average income per production}

The deduction of all expenses related to the production of seed cotton, leaves an average annual income of 150,000 to 200,000 FCFA per hectare. However, the annual income calculated on the basis of field results, shows that there are some producers below this threshold.

In addition, the cotton growers of the Arrondissement do not assess the loads during cultivation operations, nor the working time of the physical energy deployed. This takes up about $45 \%$ of the producer's income. From the equation: Gain $=$ selling price - (purchase price of inputs and other charges), we can deduce that producers are making losses. It is noted that these producers do not buy the food products, since after the cotton harvest, they have the chance to cultivate the cereals through the second rainy season which are profitable. In the case of those who incur debt, they sell part of the grain to pay it back. From this, it can be deduced that cotton is more beneficial to cotton growers and their domestic and foreign trading allies than to producers. Those who have earnings make some achievements.

\subsubsection{Destination of income from cotton production}

The cultivation of cotton provides income in the life of the populations. These incomes make it possible to solve certain social problems. From this income they derive from cotton production, producers produce consumer goods and equipment. Indeed, people interviewed said they bought a means of transport (motorbike), others were able to buy plots, farmland, etc.

Profits allow some to build or improve their homes and others to meet social needs, children's schooling and many others (Figure 2). 


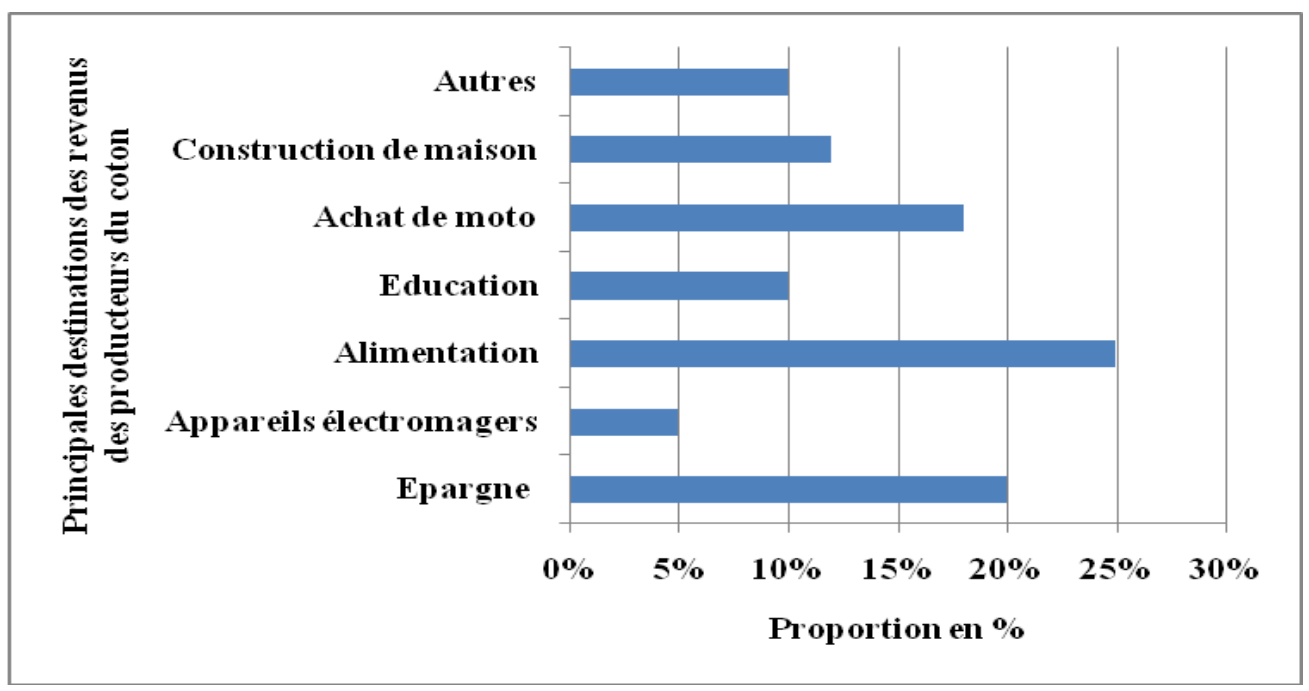

Figure 2: Main destinations of agricultural income for cotton producers.

Source: Field survey, July 2020.

The analysis of figure 2 reveals that cotton producers in the Aklamkpa district devote the financial means to family investments: food for $25 \%$, savings for $20 \%$, the purchase of motorbikes for $18 \%$. , house building for $12 \%$, children's education for $10 \%$, purchase of household appliances for $5 \%$ and other destinations for $05 \%$.

Plate 1 shows some photos of individual goods acquired by cotton growers with income from cotton production.

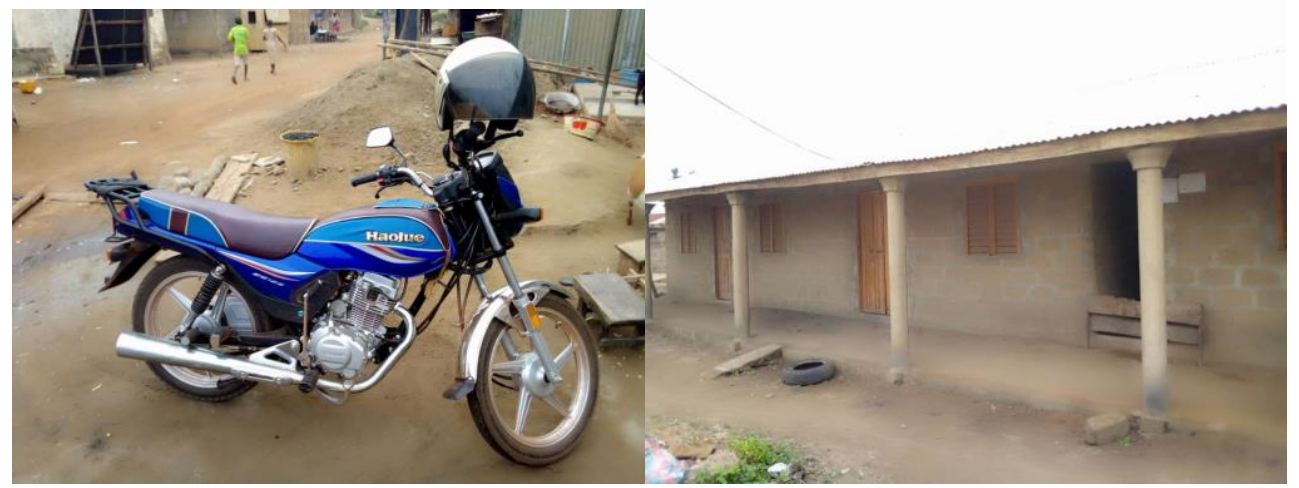

1.1. Motorcycle purchased by a Lagbo 1.2 producer. House built by a producer of Affizougo (2018-2019 campaign Shooting: Tchaou G., July 2020

Plate 1: Goods acquired by cotton growers 
The plate shows photo 1.1 which is a motorcycle acquired by a cotton farmer and photo 1.2 , a house built following the agricultural campaign (2018-2019).

Plate 2 shows the community achievements made with the income from the marketing of cotton by subscriptions from producers.

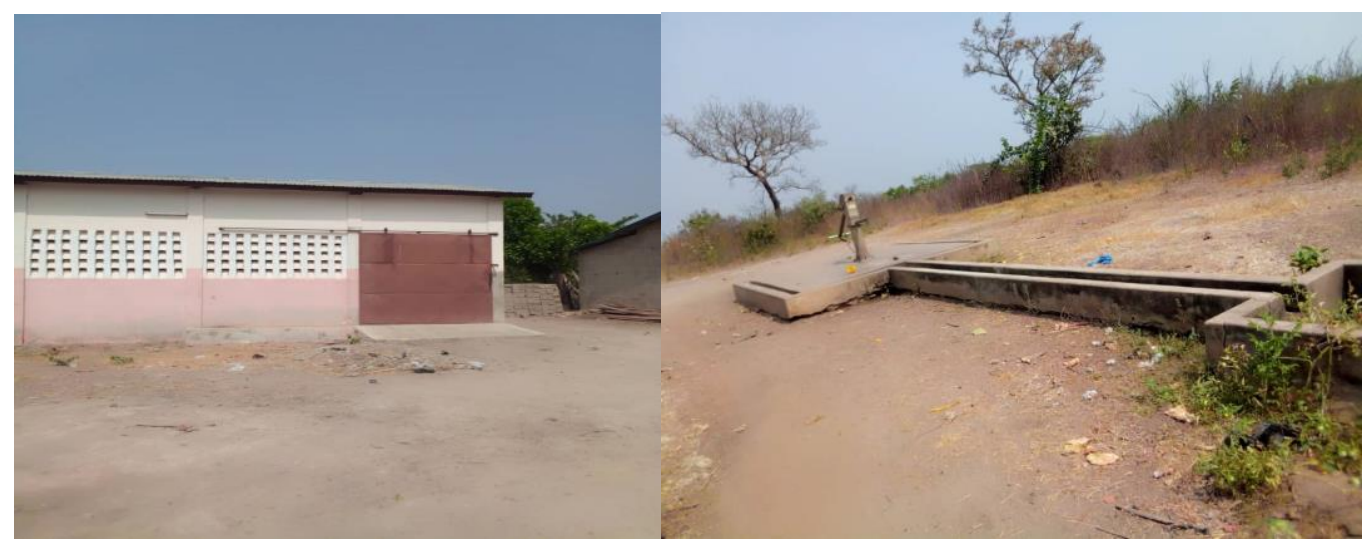

Plate 2: Achievements made by cooperatives

(2.1 photo of a hand pump for which the villagers have made their financial contribution, 2.2. Photo of a storage warehouse built entirely by the producers)

Shooting: Tchaou G., July 2020

Despite its socio-economic importance, cotton production has effects on the environment. We noted here, the degradation of the plant cover, soils.

According to health workers, producers are seen in consultation and treated for skin or respiratory ailments. They do not protect themselves very well before going to spray their fields or are exposed to the wind when spraying with insecticides.

\section{DISCUSSIONS}

Cotton is the main export product in Benin (A. Gbetoenonmon and J. Gbeffo, 2016). Benin is also rightly ranked third behind Mali and Burkina Faso among West African cotton-exporting countries. About $95 \%$ of cotton lint production is exported, accounting for $80 \%$ of export earnings and contributing significantly to improving the national trade balance (ONS, 2013).

The cotton sector is recognized as one of the flagship sectors of Beninese agriculture and generates income for most of the populations of the Center. (D. Biaou et al, 2016, p.210); (S. Tovignan et al, 2014, p.1) and (A. Paraïso et al. 2012, p.104).

The concentration of this activity in the study area is of paramount importance for the national economy and can play an essential role in the process of economic and social development. Thanks to the size and organization of the country's cotton sector, most producers resort to loans in the study area. This is contrary to the results of studies by (R. Yegbemey et al, 2014, p.278) 
Vol. 06, No. 05; 2021

ISSN: $2456-8643$

which showed that access or use of credits by producers in northern Benin is very low due to the fact that agriculture is largely a more family-oriented agriculture whose financing for this activity comes from the personal savings of producers. It is observed that very few cotton producers in the study area are educated because cotton production does not require educated labor for the various operations, in particular weeding, phytosanitary treatment and harvesting. The preference for producers would be to satisfy the need for labor by increasing the number of women and also by keeping the majority of children on their farm or by dropping out of school those who are old enough to work actively in the cotton fields. .

The results of this study show a great conformity with those obtained in previous studies. According to A. Paraïso et al. (2012, p.102) who carried out their studies in central and northern Benin, cotton cultivation is profitable and generates a positive net margin $(13,600)$ of between 225,100 FCFA and 192,467 FCFA. For (S. Zimé, 2015, p.61), cotton-producing farms in North Benin were able to generate a net margin of CFAF 75,713.45 / ha. These results confirm those obtained by the present study which indicates that cotton cultivation generates a net positive margin (22 684.2 FCFA / ha). In short, cotton production is economically profitable from the point of view of the net margin generated.

It should also be noted that cotton production leads to poor remuneration of the family labor force in the study area. The internal rate of return in the study area does not allow a cotton producer to borrow money from Micro Finance Institutions at the interest rate of $24 \%$, because he will not be able to repay the loans. interest from the net margin from its cotton production. In other words, the net profit from cotton production does not allow a producer to make profitable his production.).

\section{CONCLUSION}

At the end of this study, it should be remembered that agriculture is the pillar of all rural activities given the number of people it employs and the volume of its production. Cotton cultivation is at the heart of this agriculture in the intertropical regions, especially in Africa. It remains the most important industrial culture in Benin. But this culture has huge socio-economic and environmental impacts in Aklamkpa Ward.

Income from cotton marketing does not allow producers to fully meet their needs. The cultivation of cotton contributes thanks to the rear effect of fertilizers to develop food crops that allow producers to meet their basic needs, in particular that of subsistence. However, fluctuating cotton costs on the international market, internal mismanagement of CVPCs and irregular rainfall lead to worsening of the living conditions of producers. As a result, cotton is sometimes not profitable for farmers.

\section{REFERENCES}

AFOUDA Fulgence, 2010, "Current rainfall trend at the start of the agricultural season in the departments of Mono-Couffo", Annales de l'Université de Lomé, Série Lettres et Sciences Humaines de Lomé (Togo), Tome XXX-2, p. 133-142.

AFOUDA Fulgence, SALAKO Magloire Pierre and YABI Ibouraïma, 2014, "Interseasonal instability of the rains during the great agricultural season in the commune of Kétou in Benin", 
Vol. 06, No. 05; 2021

ISSN: $2456-8643$

Geography Review of Leïdi Laboratory (RGLL) "Territories and Development Dynamics" $n{ }^{\circ} 2$, p. 26-47.

BATAMOUSSI Hermann. M., Moumouni I., and Orou Tokore Mere S.B.J, 2015, "Contribution to the improvement of peasant practices for the sustainable production of cotton (Gossypium hirsutum) in Benin: case of the municipality of Banikoara", Int. J. Biol. Chem. Sci., Vol. 9, no 5, pp. 2401-2413.

BIAOU, D., Yabi, Jacob. A. Yegbemey R., N., \& Biaou, G., 2016, Technical and economic performance of cultural practices for the management and conservation of soil fertility in vegetable production in the commune of Malanville, North Benin. International Journal of Innovation and Scientific Research ISSN 2351-8014 Vol. 21 No. 1 Mar. 2016, 201-211.

DGAE, 2020, Recent developments in the Beninese economy. Cotonou: Ministry of Economy and Finance. P.1-8

DOSSA Judicaël .Urbain., 2007 , Agricultural activities and standard of living of rural populations: Case of the Municipality of Savalou, Master's thesis in geography, UAC / FLASH / DGAT, 71p.

DOSSOUNON I., 2003, Socio-economic analysis of peasant practices of phytosanitary production against pests in the production and conventional systems of cotton in the Arrondissement of Setto Municipality of Djidja, Agronomist thesis, ESR, University of AbomeyCalavi, FSA, Benin, 70p + annex.

GBETOENONMON Abel and Gbeffo J., 2016, "Study report on the financing strategies of the World Bank in the agricultural sector in Benin", Cotonou, Benin, p.49.

HOUNDEKON Victorin.A., 2010, "Comparative analysis of organic cotton and conventional cotton production systems in Benin", Benin, pp. 1-13.

HOUGNI A., Kpadé P.C. and Djihinto Angelo.Cocou, 2012, "Organic cotton cultivation and fair trade in cotton: Two niche approaches", Bull. the Rech. Agron. of Benin, no 229, p. 884.

INSAE, 1979, 1992,2002 and 2013, General population and housing censuses (RGPH 1, 2, 3,4) Cotonou, Benin.

OGOUWALE Euloge, 2006, Climate change in southern and central Benin: indicators, scenarios and foresight of food security, Single doctoral thesis Pluridisciplinary Doctoral School of the University of Abomey-Calavi, $302 \mathrm{p}$.

ONS, 2013, "review of the 2012-2013 transitional campaign", Cotonou, Bénin, pp.1-11.

ONS, 2015, "Baseline study on the establishment of the seed cotton purchase price smoothing fund in Benin", Provisional report, Cotonou, Benin, pp. 1-73. 
Vol. 06, No. 05; 2021

ISSN: 2456-8643

PARAÏSO, A., Yabi, A. Jacob., Sossou, A., Zoumarou-Wallis, N., \& Yégbémey, R. N., 2012, Economic and financial profitability of cotton production in OUAKE in North-West Benin. Annales des Sciences Agronomique 16 (1): ISSN 1659-5009, 91-105.

TOVIGNAN, S., Hinvi, J., Glin, L., \& Sodjinou, E., 2014, Determinants of the profitability of African cotton production on Organic Agriculture. 3rd Western Conference (p. 1). Benin: Cotonou.

YABI Ibouraïma, 2007, "Rainfall crisis and cotton production in 2007 in the Collines Department in Benin", Semi-annual review of the Geography of Benin n ${ }^{\circ}$ 2, DGAT / UAC, p. 43-56.

YABI Ibouraïma and AFOUDA Fulgence, 2008, "Rainfall variability at the start of the agricultural season and adaptation measures in the Collines Department in Benin (West Africa)", Proceedings of the UAC conference on Sciences, Cultures and Technologies, "Geography " series, UAC, Benin, p. 315-327.

YEGBEMEY, R., Yabi, Jacob., Aïhounton, G., \& Kokoye, S., 2014, Economic valuation of maize farming profitability under climate change adaptation in Benin, West Africa. Int. J. Agric. Resour. Gov. School. 10, 269-280.

ZIMÉ Sila A., 2015, Cotton cultivation in the Municipality of Sinende: Diagnosis, Master's thesis in geography, UAC / FLASH / DGAT, 81p. 